\title{
CATALYSIS OF STRATEGIC PLANNING FOR SMALL BUSINESS
}

\author{
Harold W. Fox \\ Department of Marketing, Finance and General Business \\ Pan American University \\ Edinburg, Texas
}

Analysis of the roles and pitfalls of substitute directors who accelerate strategic planning in small firms is the purpose of this paper. It discusses why small companies have use for substitute directors, how they are organized into a quasi-board, and what they do.

The first need of a small business, says Peter Drucker, is strategy $(4, p$. 469). Indeed, research confirms, small companies that engage in strategic planning are significantly more successful than those that do not $(8$, p. 92). Anything that would enhance the small businesses' precarious survival probabilities $(9$, pp. $28,31,148)$ would seem worth doing. But most small firms eschew strategic planning (11, p. 25). Apparently many ownermanagers lack the requisite temperament and tools. Daily crises absorb their time and keep them too busy to plan-although many of these crises might have been forestalled with adequate planning.

Even if owner-managers recognize the need and their own inability to cope with strategic planning, they cannot turn to all the sources of help that are available to larger organizations. They do not have, and do not want, planning personnel or other staff people. Strategy formulation is not suitably delegated to consultants since, typically, strategies prepared by others are not used (12, pp. 289-293). The board of directors of a large corporation has overview of strategic planning as one of its duties. No such institution exists for the proprietor or partner. In small, close corporations the board's exercise of its functions is usually nominal $(2$, passim).

\section{Enter: Quasi-boards}

To resolve this dilemma, some chief executives have instituted quasiboards of directors (1, p. 103 and 7). These advisory councils act as if they were large-corporation conventional boards of directors. They guide the independent businessperson and the firm's top cadre to formulating and implementing strategies. The operative word is "advisory." Logic and persuasion instead of legality and power are their tools. 
The accompanying exhibit illustrates the position of each style of board within a corporation. The conventional board has the authority to govern; the chief executive officer is its subordinate. The quasi-board advises; it is subordinate to the chief executive. The conventional board of directors is official. The quasi-board is informal. Thus, even in a small corporation where both types of boards may exist, there is no conflict of roles.

This informal status is important to the efficacy of quasi-boards. It may make the recruiting process, to be discussed subsequently, easier because members do not assume legal obligations. It frequently makes the adviseand-suggest role more effective because members are no real threat to the owner-manager. The latter appointed them and can dismiss them.

Owner-managers are psychologically set to hear-and to act upon-the advice they are soliciting. They are more willing to discuss the businesstheir secrets, ideas, errors, and apprehensions-with this nonthreatening group. And they are assured that such disclosures will remain confidential with the well-chosen council. Members have no legal mandate and no disclosure requirements. This trust provides a necessary basis for a consultative relationship. In this milieu, examples will demonstrate later, strategic planning is apt to be sound. But such an atmosphere does not develop by happenstance. It derives from judicious organization of the quasi-board.

\section{CORPORATE ORGANIZATION CHART SHOWING LEGAL RELATIONSHIPS}

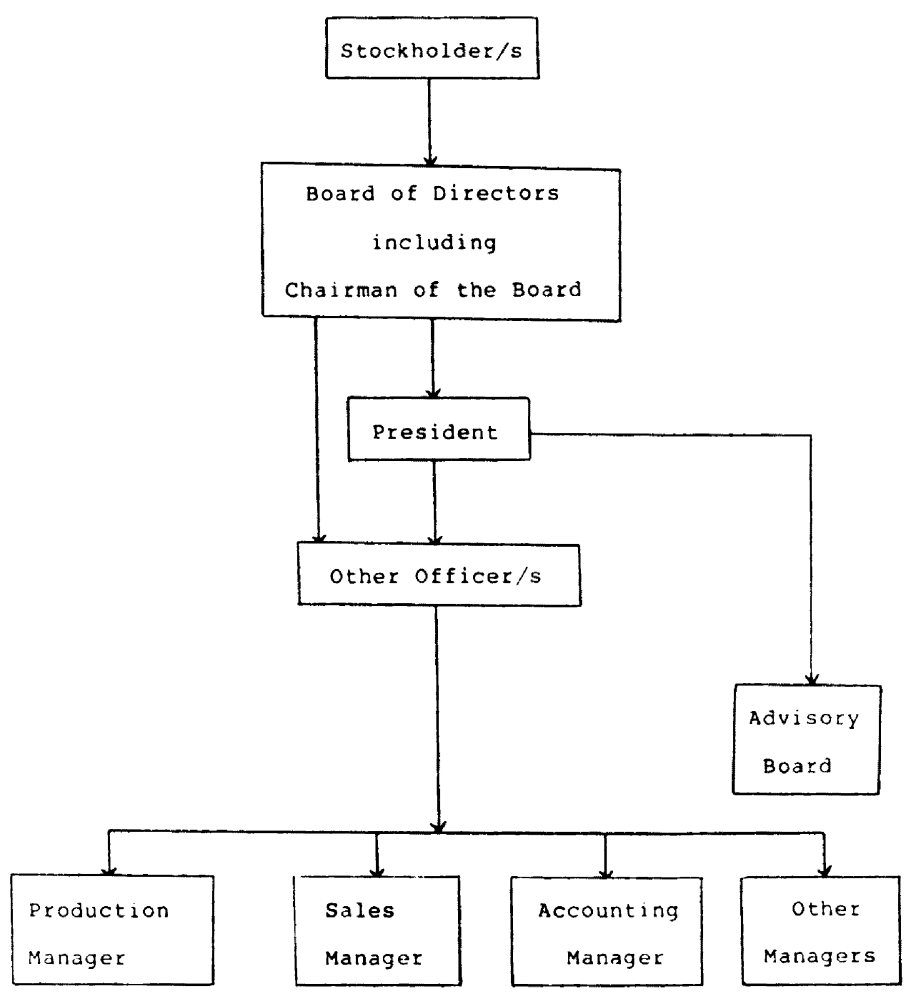




\section{Organizing a Board}

An effective quasi-board is small. It comprises three or four outsiders and perhaps two key managers. The owner of the business presides.

Astute owner-managers seek mentors who are constructive and practical. They invite business acquaintances, owners of noncompeting businesses, speakers or registrants at executive seminars, local professional people, and trusted friends. An important qualification of independent members is that the owner-manager respect their judgment. "You have to be willing to listen to the members," says Dick Flaute, a wholesaler. "And they have to be strong enough in their personalities to make you listen" (6, p. 42).

Are people of this caliber willing to join? Yes, They may, in fact, be easier to recruit than the members of conventional boards of directors. The latter have come under increasing burdens of legal liabilities. Many qualified personages are reluctant to serve $(10$, p. 23$)$. But members of quasi-boards are exempt from this onus. Hence competent candidates usually are receptive to an invitation.

Motives of quasi-board members vary. Perhaps they enjoy the change of pace, welcome the broadening of their experience, or gain fulfillment. But money should not be one of the motives. Besides reimbursement of expenses, an honorarium places the relationship on a sound business basis. After all, if the advice were free, it might seem worthless. But the honorarium is modest, perhaps $\$ 500$ to $\$ 1000$ per session, which includes betweenmeetings consultations at no extra charge. This contrasts with the average annual compensation of $\$ 18,900$ for outside directors of over 600 large corporations. Additional payments were forthcoming for committee service (3, p. 1).

In the case of quasi-boards, the small fee suffices to obligate each member to treat the affiliation seriously. A higher fee could be dysfunctional. It might attract sycophants who value the income above the intrinsic satisfaction. They are liable to say whatever the chief executive wants to hear instead of giving an independent appraisal. The firm's cadre might perceive them as rivals for top-level jobs. (This has happened.) Further, a higher fee would be burdensome to many small concerns.

Council members serve at the owner's pleasure as long as they are effective. If a quasi-board fails to improve the company's strategies and performance, it constitutes a waste. Dissolution may be considered by the owner and the board members. More often, some change in staffing is all that is necessary. A few incumbents lose interest. Or conditions change. Firms encounter situations outside the ken of the panel. The owner monitors these developments. Some turnover in membership should be expected and implemented. 


\section{The Quasi-board and Strategic Planning}

One of the main purposes of organizing a quasi-board is to catalyze strategic planning. This can come about through various means, either formal procedures or, more frequently, informal evolution.

Perhaps the independent business operator has some notions about the arcane art of strategic planning but lacks the sense of urgency and/or the knowledge to get started. That owner may well include "strategic planning" in the statement of purpose or mission of the quasi-board. Occasionally, under such circumstances, structured planning becomes a regular task.

At the opposite end of the spectrum, the issue arises inevitably even if the owner does not sense the need for formal strategy. At the first orientation session for the carefully selected outside members, their initial request will be: "Define your business." This necessary exercise leads to further probes about the firm's objectives and general direction. Soon the panel has a fairly good grasp of the extent and usefulness of the firm's planning. At its urging, the formulation and review of strategies becomes a major item on future agendas.

Most quasi-boards function at some middle range between formal procedures and relaxed comradery. The informal atmosphere and lack of legal compulsions favor some middle course. The change agent can only coach and advise the owner. On the other hand, owners pay for the meeting and respect the participants' expertise. Hence they strive to present to the panel the best thought-out, most carefully prepared plans that they can devise. "My quasi-board forced me to think strategically and to formulate a plan that would meet the members' rigorous standards," notes Richard R. Yoke, chief executive officer of Technicote Corporation of Memphis, Tennessee (7). Thus this institution not only preserves but actually strengthens the small businessman's independence.

The regularly scheduled meetings, quarterly or semi-annual, also provide discipline. To assure productive use of meeting time, owners prepare and distribute briefing papers, financial statements, budgets, and an agenda. In the course of doing so, they review their firm's current position and plans for the future. Meetings focus on the substance of the strategy. All aspects are explored. The technical familiarity of the inside board members balances the broad perspectives of the outsiders. Jointly, they seek to build on the company's strengths and to shore up or de-emphasize its weaknesses. Thanks to the diverse backgrounds of the participants, inputs are practical ideas and suggestions. Synergy ensues. To sharpen the analysis, one member might even play "devil's advocate."

After a strategy has been adopted by consensus, it is recorded in the meeting minutes. At the next session the first order of business will be the owner's report on the implementation of the strategy and on the results to date. 
This format exerts strong pressure for strategy formulation and execution. The business chief (perhaps also the concern's top lieutenants) is directly involved in devising the strategy. He or she is psychologically committed to carrying it out and reporting outcomes to the advisory panel.

\section{Scope of Deliberations}

Compared to a large corporation, small firms have simpler strategies. Formulation procedures are somewhat haphazard. The owner's intimate familiarity with customers, production processes, and industry characteristics substitutes for multiple planning tiers, sophisticated techniques, even formal research and environmental scanning. These realities favor the use of an auxiliary mechanism such as a quasi-board. With adequate preparation, it can be an effective and efficient catalyst, producing results in a single meeting. A few examples (mostly 7) show some catalysts in action and reveal the breadth of coverage.

*Two-hour sessions for formulating a growth strategy are customary at Dayton Plumbing Supply, Inc., Dayton, Ohio. The company's president formed a quasi-board several years ago to surmount a plateau in sales. Since then, sales have doubled (6, p. 42).

*The quasi-board of Krizman, Inc. of Mishawaka, Indiana, cleared the air for the owner and the newly appointed general manager by verifying and supporting various strategic policy changes that the latter had instituted.

*At another privately held firm, the quasi-board arbitrated between a conservative septuagenarian owner and his daughters who sought to revolutionize strategies.

${ }^{*}$ Bank of Mid Jersey has long maintained three advisory boards corresponding to its segmentation: farming, business, and consumers. Each council recommends strategies within its purview.

*After orientation, the newly formed advisory board of Sterling Magnetics Pvt. Ltd. in Goa, India, pondered banking relations, excise tariffs and sales taxes, inventory control, production and subcontracting policies, and personnel.

*At Chapel Electric Co. of Dayton, Ohio, the "four-member advisory board made me do a lot of planning," says Fred Setzer, Jr., president. He credits his board with assisting in this firm's growth (6, p. 42).

*Divestment of a hardware store and farm supply operation was one of the recommendations for Deli Inc. of Millston, Wisconsin. The sole stockholder was reluctant at first, but says he is now glad he acceded to his advisory council $(5, \mathrm{p}$. C-1).

${ }^{*}$ Foothill Bank in Mountain View, California, uses its advisory panel for two-way communication with the local population. Members meet to discuss the bank's new strategies and provide officers with feedback from the community. 
Although other examples could be adduced, it should be evident that anything of strategic importance is suitable for consideration by a quasiboard. The following comment is typical: "I designed my advisory council so it would fit my company's needs and compensate for my personal weaknesses" (7). These two factors are critical. Constructive recommendations for a firm's strategy and compatible chemistry with the owner are the two major criteria of the catalyst's effectiveness.

\section{Evaluation}

Realistic goals, prudent selection of outside members, and capable administration of quasi-boards can lead to useful contributions. Owners report that they divert much more time from hands-on management to strategic planning and board procedures than they expected. Moreover, full disclosure to the panel is a prerequisite for constructive performance. Boards of companies that withheld financial statements and other particulars failed.

Astute owner-managers do not expect miracles. Outsiders need some time and guidance to learn the intricacies of the business. But suggestions in the realm of generic business strategy should be forthcoming quickly. After two or three meetings, a quasi-board should reach optimum effectiveness.

Well-functioning councils broaden managerial expertise and present objective inputs for strategic decisions. But they are not universal panaceas. For example, a group is usually unsuitable for coping with a crisis. Emergencies of strategic import do not wait for a board to convene and deliberate. In a crisis, one person has to take charge decisively. This person is ordinarily the business owner who retains full responsibility for results. In practice, the owner often calls on one board member who has the particular qualifications needed in that crisis.

Another intractable challenge for a quasi-board is familial conflict, a common occurrence in closely held companies (2, passim). The board is supposed to be objective, yet the issue is largely emotional. Boards tend to recommend what seems best for the business. This may not satisfy the owners. Quasi-boards cannot relieve owners of personal problems or major decisions.

Altogether, as has been shown, the combination of a persuadable proprietor and a proficient panel can help a business thrive. The main benefit of a quasi-board, many entrepreneurs report, is that it requires them to formulate explicit strategies justifiable to critical experts. The catalyst's challenge, on the other hand, is to instill professional discipline in the firm's management without impairing the owner's creative entrepreneurship.

\section{REFERENCES}

1. Cohn, T. and R.A. Lindberg (1974), Survival \& Growth. AMACOM, New York. 
2. Danco, L. (1975), Beyond Survival. Reston Publishing Co., Inc., Reston, Va.

3. Deloitte Haskins + Sells (April 27, 1984), "Survey of Board Practices," The Week in Review.

4. Drucker, P.F. (1973), Management. Harper \& Row, Publishers, Inc., New York.

5. Jouzaities, C. (February 23, 1983), "Advisory Panels Offer Good Advice at a Cheap Price," Chicago Tribune.

6. Kunde, D. (June 17, 1984), "Advisory Panel Aids 'Little' Guy," Dayton Daily News.

7. Personal experience, interviews, or correspondence.

8. Robinson, R.B. (March 1982), "The Importance of Outsiders in Small Firm Strategic Planning," Academy of Management Journal.

9. Reagan, R. (1983), The State of Small Business: A Report of the President. U.S. Government Printing Office, Washington, D.C.

10. Rout, L. (March 3, 1981), "Job of Corporate Director Becomes More Susceptible to Legal Assault," Wall Street Journal.

11. Sexton, D.L. and P.M. Van Auken (July 1982), "Prevalence of Strategic Planning in Small Business," Journal of Small Business Management.

12. Steiner, G.A. (1979), Strategic Planning, Free Press, New York. 